\title{
REFLEXÃO SOBRE A NATUREZA DO PROJETO
}

\author{
Patrícia Helen Lima* \\ *Arquiteto Urbanista, Mestre em Projeto Sustentável pela FAUUSP, \\ Doutoranda em Arquitetura e Cidade pela FAUUSP \\ Coordenadora da Seção de Informação da Qualidade Ambiental da PMSBC \\ E-mail: patricia.helen.lima@usp.br
}

\begin{abstract}
RESUMO
Conhecer, Compreender e Proteger a natureza que nos dá a vida, entendendo seus limites e inter-relacionamentos e admitir que projetos manifestam a intenção humana e interferem na natureza modificando o ambiente é o primeiro passo para pensar na construção de projetos com responsabilidades acima da visão pontual de uma ação e possibilitará trazer em si identidade com o local, partilhando as qualidades e a condição da natureza influenciando na forma urbana e dando-lhe melhores condições estéticas, funcionais e de qualidade ambiental.
\end{abstract}

Diante da complexidade das relações homem-natureza, propomos a leitura da paisagem, definindo diferentes tipos de Unidades de Paisagem em função das relações estabelecidas nas formas do uso do solo que definem o espaço e a partir do inventário do território propor uma infraestrutura verde que oriente o desenvolvimento e a proteção da natureza. O uso do solo vem diminuindo áreas verdes protetoras e aumentando áreas impermeáveis e asfaltadas, elevando a temperatura e acarretando o processo de ilhas de calor.

As infraestruturas devem funcionar sem causar danos e em comunhão com a natureza para garantir a qualidade da vida. Temos o desafio de enfrentar transformações pela resiliência às mudanças climáticas induzidas pelo uso do solo e demonstrar como a arquitetura desempenha papel de liderança para lidar com grandes questões ambientais e de sobrevivência.

Palavras-chave: Paisagem, Forma urbana, Infraestrutura verde, Ilhas de calor, Resiliência às mudanças climáticas. 


\title{
REFLECTION ON THE NATURE PROJECT
}

\begin{abstract}
Knowing, Understanding and Protecting nature that gives us life, understanding its limits and interrelationships as well as recognizing that projects manifest the human intention, interfering, consequently, with nature by modifying the environment, is the first step to think about the construction projects with responsibility above the punctual vision of an action and will allow itself to bring identity with the place, sharing the qualities and condition of nature influencing urban form and giving better conditions aesthetic, functional and environmental quality.
\end{abstract}

Having in mind the complexity of human-nature relationships, we propose a reading of the landscape, defining different types of Landscape Units vis-à-vis the relations established with the ways of land usage, defining the environment and starting from the territorial inventory propose a green infrastructure that guides the development and environmental protection. The land usage is reducing the protective green areas and increasing impermeable areas and paved grounds, raising the temperature and causing formation of urban heat islands.

The infrastructure must work without causing damage and in communion with nature to ensure quality of life. We have the challenge of facing the transformations by the resilience to the climate change induced by the land usage as well as demonstrate how architecture plays a leadership role to deal with great environmental issues and survival.

Keywords: Landscape; Urban Shape; Green Infrastructure; heat islands; resilience to climate change. 


\section{INTRODUÇÃO}

A natureza envolve vários sistemas inter-relacionados, que implica na adoção de um processo sistêmico para que se possa compreender e tratar das relações entre Homem e o meio físico e das interações existentes entre eles, entendendo que Homem e natureza têm uma conexão em suas relações, não sendo possível reduzir um ao outro, ao mesmo tempo em que se distinguem se ligam (TRES, 2010).

Nesta perspectiva integradora, busca-se a qualidade ambiental conciliando a esfera ambiental, social e econômica na organização do espaço e a concepção de paisagem ajuda no entendimento de suas conectividades, percebendo que a paisagem reflete as características do todo que a compõe. Isto leva a implicações sobre as intervenções que modificam a paisagem moldada de acordo com as necessidades e desejos do homem e da sua adaptação nesta paisagem, gerando uma complexa dependência entre o homem e o meio físico.

O inventário da paisagem relacionado às ações de uso do solo possibilita criar diretrizes para intervenções no ambiente e projetos que definam com equilíbrio o uso e a natureza, partindo do princípio de que a natureza foi e está sendo modificada, e muito dificilmente poderá ser restaurada à sua condição original em função das exigências do modelo econômico de ocupação do espaço, sendo necessário refletir como construir com capacidade de perceber a paisagem acima das visões particulares.

É necessário lembrar a influência do uso do solo nas mudanças climáticas, que acarretam importantes modificações nas variáveis meteorológicas como a temperatura que se eleva resultando em um fenômeno chamado llhas de calor, refletindo em má qualidade para a vida.

\section{UNIDADE DE PAISAGEM}

A Unidade da Paisagem é definida como um recorte territorial que apresenta homogeneidade de configuração, caracterizada pela disposição e dimensão similares dos elementos definidores da paisagem: o suporte físico, a estrutura e a função, considerando o padrão de drenagem, a cobertura vegetal e a forma de ocupação.

A estrutura é entendida como a relação espacial entre elementos da paisagem: fragmentos, corredores e matriz que compõem os componentes bioecológicos e os geoecológicos, composto pela hidrologia, geomorfologia, pedologia. A função é a interação entre os elementos espaciais, responsável por moldar a estrutura da paisagem (FORMAN, 1995). 
A estrutura observada a partir dos três elementos básicos é definida por:

- Matriz - Elemento que tem o domínio ou que controla a dinâmica da paisagem;

- Fragmento - Manchas não lineares que interrompem a matriz;

- Corredor - Elementos lineares e distinguíveis na matriz;

- Mosaico - Presença de dois ou mais elementos. Forman (1986) analisa mancha, corredor e matriz conjuntamente para formar mosaicos, o qual é evidente em todas as escalas.

Grande parte das cidades passou pelo processo de grande adensamento urbano que acarretou consequências, como a perda de ventilação natural, aumento da temperatura, concentração de poluição, menos sombreamento, menos habitat para a fauna e poucos vazios que representam oportunidades de preservação e lazer. As áreas construídas são extensas e os projetos cada vez menos compatíveis com a natureza dos sítios em que se instalam, acarretando perda de qualidade de vida.

Os espaços livres, tanto urbanos quanto rurais, na grande maioria estão isolados, dificultando a criação de redes que permita maior biodiversidade nas cidades, que componham um sistema interligado e que permeie a matriz urbana desempenhando papel ecológico, integrando diferentes espaços. O enfoque estético perde a proporção na medida da destruição do equilíbrio de cheios e vazios para a harmonia das intervenções de projeto.

A malha viária é tida como alicerce do crescimento e espraiamento da cidade, ampliando o uso e escoamento de veículos, fragmentando o espaço, interrompendo áreas vegetadas e muitas vezes representando barreira física à conexão das áreas construídas com os espaços livres.

Os corredores naturais, que possibilitam a integração dos espaços por sua função legítima, deixam nas áreas urbanas de cumprir este papel em função das mudanças de sua drenagem natural.

Nesta concepção, a definição de unidades espaciais, a partir da compreensão das áreas que contenham intervenções e pressões sobre os sistemas naturais ou criados pelo homem, pode ser agrupada de acordo com suas características. FORMAN (1986) 
observou uma porção da paisagem modificada em uma matriz natural sem impacto humano significativo e uma paisagem urbana consolidada e definiu diferentes padrões de desenvolvimento para agrupar áreas com mesma característica:

PAISAGEM NATURAL - Matriz altamente conectada, baixa densidade de manchas e corredores. Pouca influência humana;

PAISAGEM MANEJADA - Matriz permanece ampla, embora seja dominada por uma ou poucas espécies que são manejadas para produção. A matriz é afetada primordialmente pela colheita de produtos. Pequenos conjuntos de casas são presentes, corredores de comunicação e colheitas em abundância, cortando abundantemente a conectividade da matriz. Espécies de animais desaparecem;

PAISAGEM CULTIVADA - Sistema social que diretamente controla a terra e a prática de uso. Extensivas planícies são cultivadas e tipicamente dividido o solo para a troca do tipo de plantio de acordo com a estação. A população é moderadamente densa.

PAISAGEM URBANA - Geralmente variada porque cidades assumem várias funções. A relativa homogênea desorganização transforma a paisagem numa estrutura organizada. Sugere que a ordem física das comunidades urbanas é comparada fundamentalmente a ordem orgânica dos organismos. A paisagem urbana é composta de dois tipos de elementos da paisagem: ruas e quadras com uma dispersão de parques e outras paisagens incomuns. Normalmente é o resultado das características culturais e do sistema político. Poucos animais e espécie de plantas reproduzem na cidade. $\mathrm{O}$ acúmulo do lixo e esgoto é uma das consequências da urbanização que afeta diretamente a paisagem. Todas as áreas abertas são de excepcional importância para a biodiversidade. De toda forma, a cidade é também um sistema ecológico, espacialmente sobreposto e com pouca conexão. A grama da cidade, as árvores e outras plantas oferecem suporte a uma estrutura ambiental bastante simplificada.

Outra influência humana sobre a paisagem que deve ser considerada é a desertificação, desmatamento e erosão, para entender como as pessoas afetam a paisagem, através de políticas, economia e decisões sociais. Assim, na composição das diretrizes são relacionados junto às Unidades de Paisagem as formas do relevo (geomorfologia) e as bacias hidrográficas, o que definirão as ações do homem determinadas nas Unidades da Paisagem e a condição natural, para que seja possível a transformação da paisagem com critérios e argumentos que lhe dão suporte. 
Neste entendimento, agrupamos as unidades da paisagem em diferentes escalas (Fig.1). Praticamente qualquer porção de terra é homogênea numa escala mais abrangente e heterogênea quando vista numa escala mais detalhada. Definir diferentes escalas permite que possa ser avaliada sua estrutura em níveis de detalhamento de acordo com a escala e desta forma, ter a compreensão do lugar em que se queira intervir com análises que transitam nas diferentes escalas, buscando o entendimento desejado do contexto.
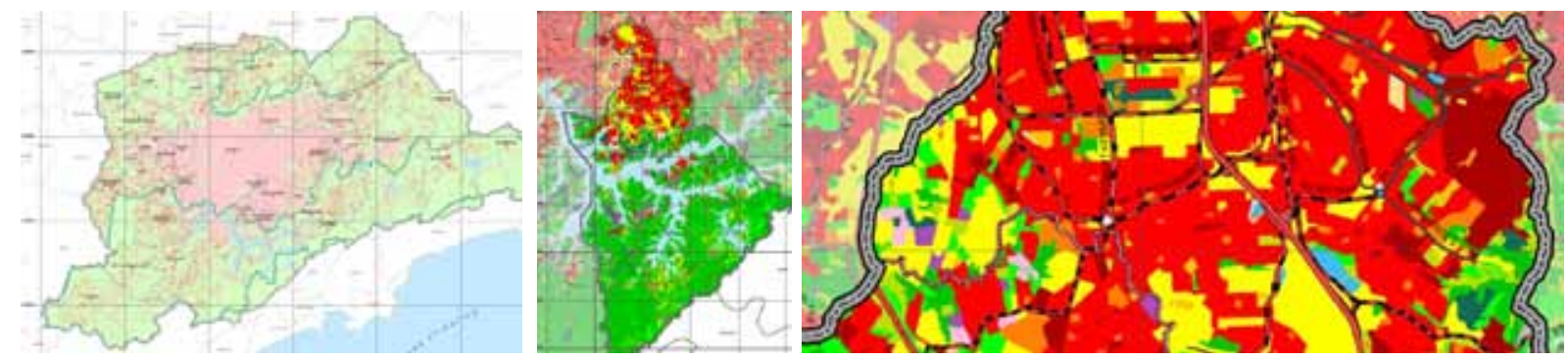

Figura 1 - Unidades de Paisagem em diferentes escalas. Fonte: Atlas de Uso e Ocupação do Solo da RMSP, 2003/ Modificado por Patricia Helen Lima (2013)

As unidades de paisagem são divididas em subunidades que possibilitam a compreensão em diferentes dimensões. Foram definidas três escalas de Unidade de Paisagem: Compartimento da Paisagem que contém a Macro Unidade; Escala de Unidades da Paisagem, que diferenciam as relações de ocupação no território como Espaço Livre e Espaço construído, Espaço de integração e Espaço de ruptura; Escala de Intervenção local, que define Usos da Terra agrupados em cada Unidade da Paisagem.

ESPAÇO LIVRE - Todas as áreas não ocupadas ou não construídas permeáveis, com ou sem vegetação. Desempenham basicamente papel ecológico, possibilitando integrar diferentes espaços;

ESPAÇO CONSTRUÍDO - Todas as áreas predominantemente construídas, verticalizadas ou não, onde a impermeabilização do solo ocorre de forma extensiva.

ESPAÇO DE INTEGRAÇÃO - Compreendidos por logradouros, cuja função é integrar os espaços construídos.

ESPAÇO DE FRAGMENTAÇÃO - Compreende basicamente Rodovias e demais logradouros que interrompem a conexão das áreas vegetadas.

A análise formulada neste contexto objetiva definir diretrizes ambientais que permitam ações concretas sobre o território e desta forma, interferir na paisagem por meio 
de elementos identificados como matriz, corredor e fragmento, buscando conexões ambientais que acolham o projeto. Os corredores que recortam a paisagem foram entendidos na direção que Forman (1995) formula em sua concepção onde a estrada é vista como um elemento de ruptura (Fig. 2) e as vias como corredores de conexão, buscando diretrizes que favoreçam a ecologia da paisagem.

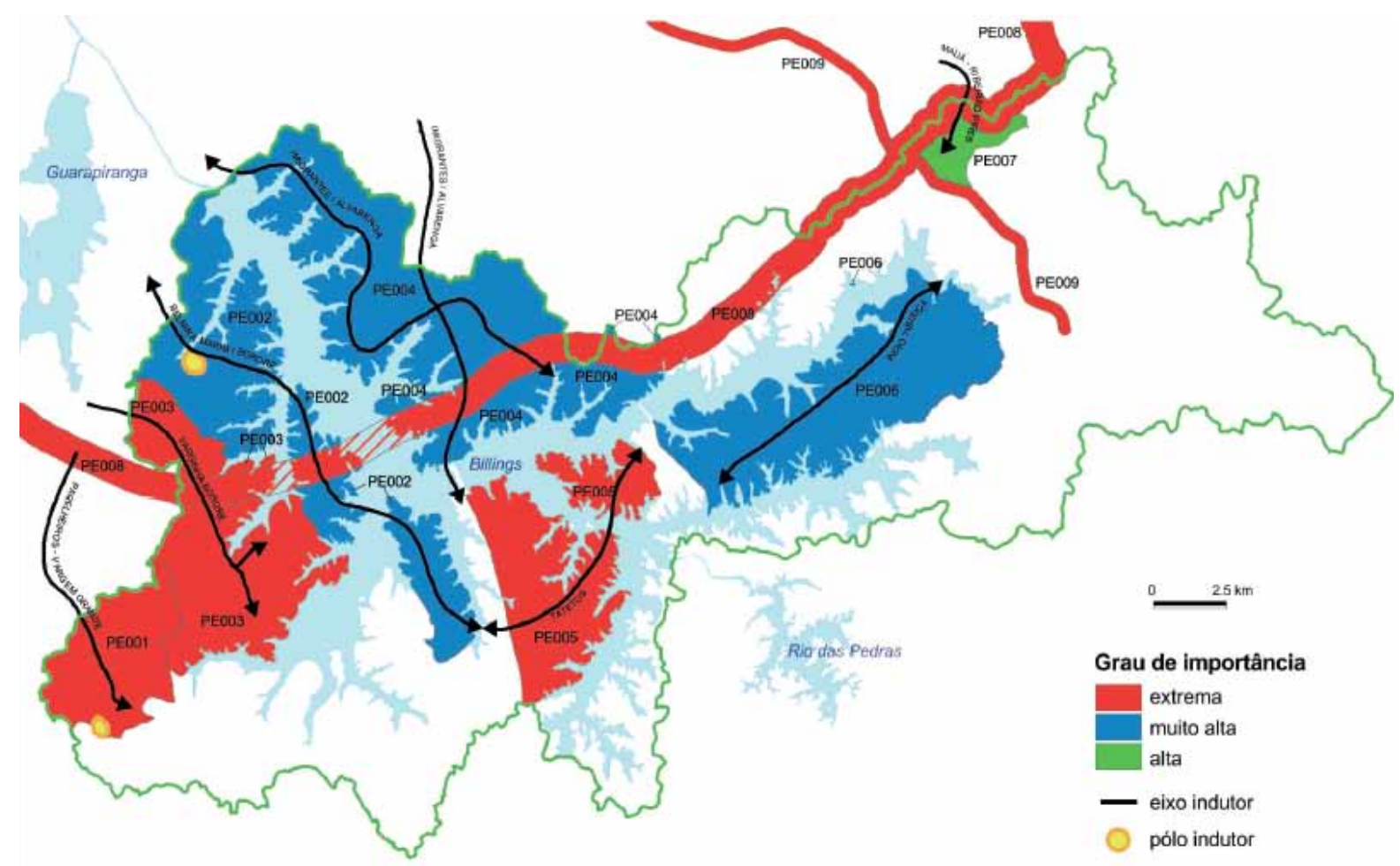

Figura 2 - Elementos de ruptura, eixos indutores. Fonte ISA, 2003.

Ainda, na composição das diretrizes são relacionados junto às Unidades de Paisagem as formas do relevo (geomorfologia) e as bacias hidrográficas, o que definirão as ações do homem determinadas nas Unidades da Paisagem e a condição natural, para que seja possível a transformação da paisagem com critérios e argumentos que the dão suporte. Procurou-se com estes corelacionamentos qualificar Unidades Geoambientais com atributos geoecológicos da paisagem e da ocupação do território.

As diretrizes ambientais refletirão onde os parâmetros físicos (Fig. 3), sem alteração significativa das características originais e as restrições legais indicarão áreas de proteção para preservação (prioritárias para controle por fiscalização, licenciamento e avaliação ambiental), áreas de proteção para conservação (onde pode ser exercido uso em harmonia com a natureza) e áreas que necessitam de recuperação (áreas prioritárias para intervenção por projetos ambientais). 

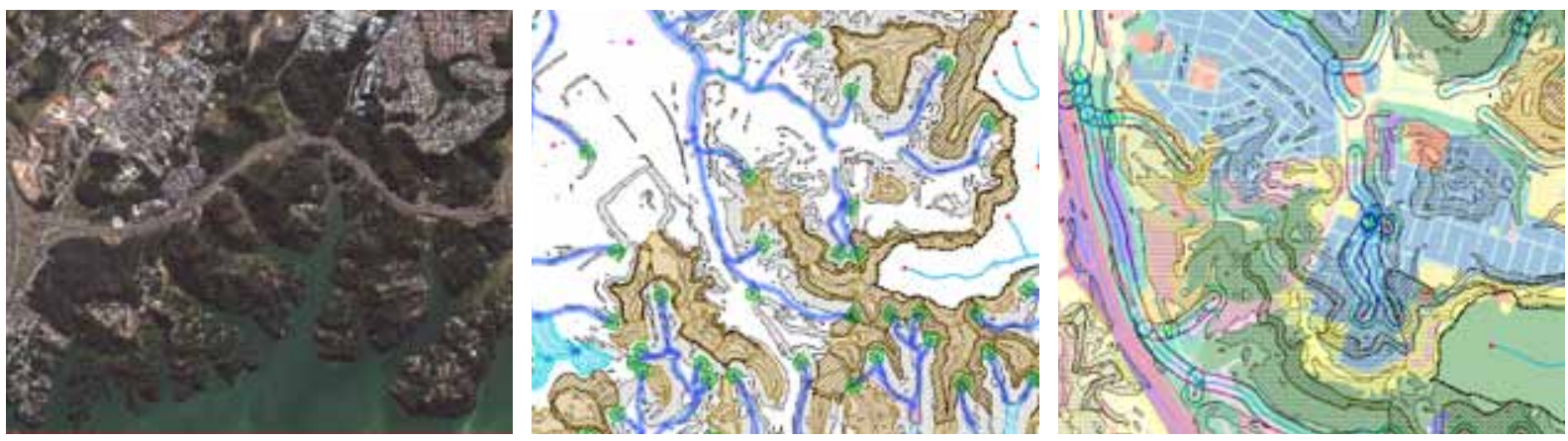

Figura 3 - Restrições legais. Fonte Atlas de Uso e Ocupação do Solo da RMSP, Emplasa, 2003.

A finalidade de classificar usos da terra e corelacionar com elementos Geoambientais é identificar um sistema de espaços livres ${ }^{1}$ (Fig. 4) capaz de criar uma infraestrutura verde como uma rede interconectada de áreas naturais e outros espaços abertos que conservam valores e funções de ecossistemas naturais, que mantenham limpos a água e o ar e que promovam uma grande variedade de benefícios às pessoas e à fauna. Neste contexto, infraestrutura verde é a base ecológica estrutural para a saúde ambiental, social e econômica, ou seja, um sistema de suporte para a vida natural (BENEDDICT, MCMAHON, 2006).
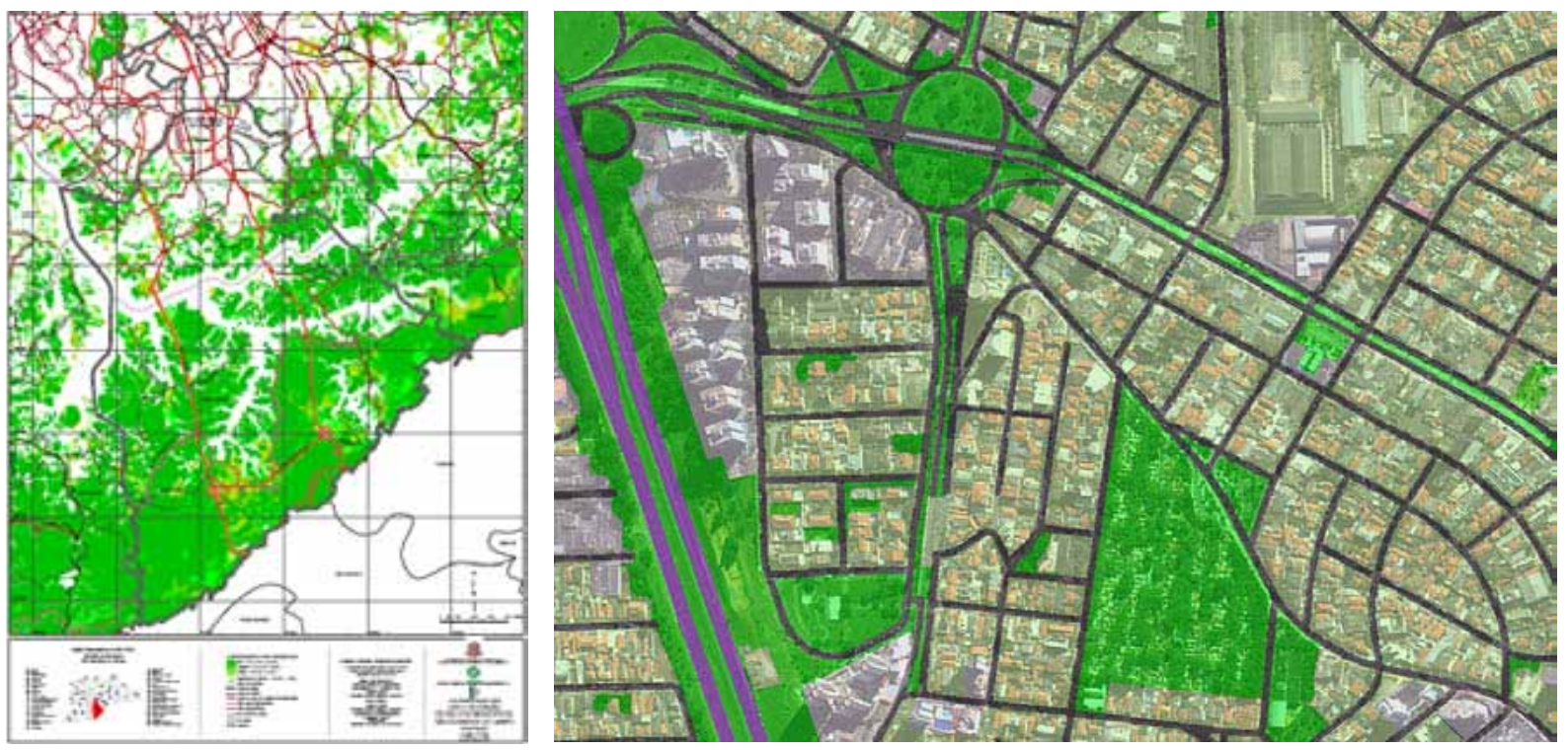

Figura 4 - Espaços livres. Fonte: Atlas de Uso e Ocupação do Solo da RMSP, Emplasa,2003

Entender a rede de infraestrutura verde ajuda a compreender quais princípios devem estar por trás de projetos e da implantação destes e permite trabalhar em direção a estratégias

\footnotetext{
${ }^{1}$ Sistema de espaços livres: Conjunto de espaços ao ar livre, destinados às pessoas, para o descanso, o passeio, a prática de esportes e em geral, ao recreio e entretenimento de suas horas de ócio LLARDENT (1982);
} 
de intervenção territorial. Entendemos a proposta da infraestrutura verde como condutora de intervenções no território, proporcionando possibilidades para a recuperação de áreas degradadas (Fig. 4) com projetos que alimentem a rede da infraestrutura verde, áreas passíveis de proteção a partir do diagnóstico ambiental e áreas para desenvolvimento.

Em paralelo a esta abordagem, caminha a análise da Qualidade Ambiental que emerge na medida da infraestrutura verde estabelecida e de tantos outros projetos de intervenções territoriais e sociais e que através de indicadores ambientais podem apontar diretrizes ou respostas às questões avaliadas e modificadas.

\section{ILHAS DE CALOR}

Especial atenção deve ser dada à ilhas de calor (Fig. 5). A urbanização impacta negativamente o ambiente principalmente pela produção da poluição, pela modificação das propriedades físicas e químicas da atmosfera, e pela impermeabilização do solo. Considerando o efeito cumulativo de todos estes impactos é o que se denomina de "ilhas de calor", definido como o aumento da temperatura de áreas urbanizadas, em relação à temperatura mais baixa da paisagem natural. Embora o aumento do calor pode se dar em área rural ou urbana, e em toda a escala espacial, as cidades são mais propícias em função de suas superfícies liberarem quantidades grandes de calor. De toda forma, as ilhas de calor impactam negativamente não somente os residentes do ambiente relacionado, mas também a outros ambientes e seus ecossistemas associados (http://www.urbanheatislands.com/).

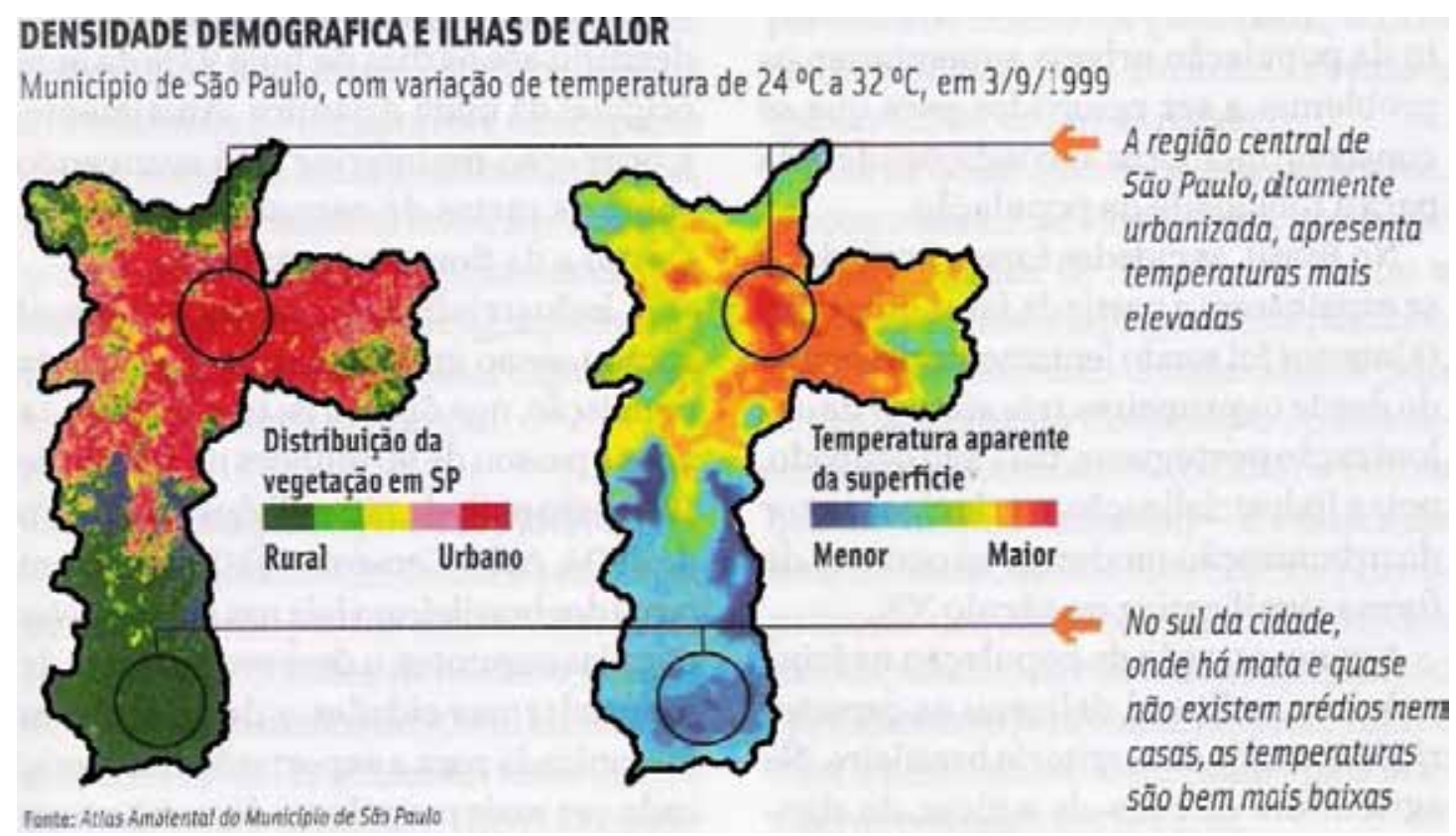

Figura 5 - Temperatura aparente da superfície. Fonte: Atlas Ambiental do Município de São Paulo. 
É conhecido que a substituição progressiva de superfícies naturais por impermeabilizações (Fig. 6), através da urbanização, constitui a principal causa da formação de ilha de calor. Superfícies naturais são frequentemente compostas por vegetação e solos que retêm a umidade. Portanto, eles utilizam uma proporção relativamente elevada da radiação absorvida no processo evapotranspiração e liberação de vapor de água, que contribui para esfriar o ar na sua vizinhança. Ao contrário, as superfícies construídas são compostas de uma elevada percentagem de materiais de construção não refletores e resistentes à água. Como consequência, eles tendem a absorver uma parte significativa da radiação incidente, que é liberada na forma de calor.

Figura 6 - Áreas desmatadas no período 1991-2000. Fonte: Atlas Ambiental do Município de São Paulo.

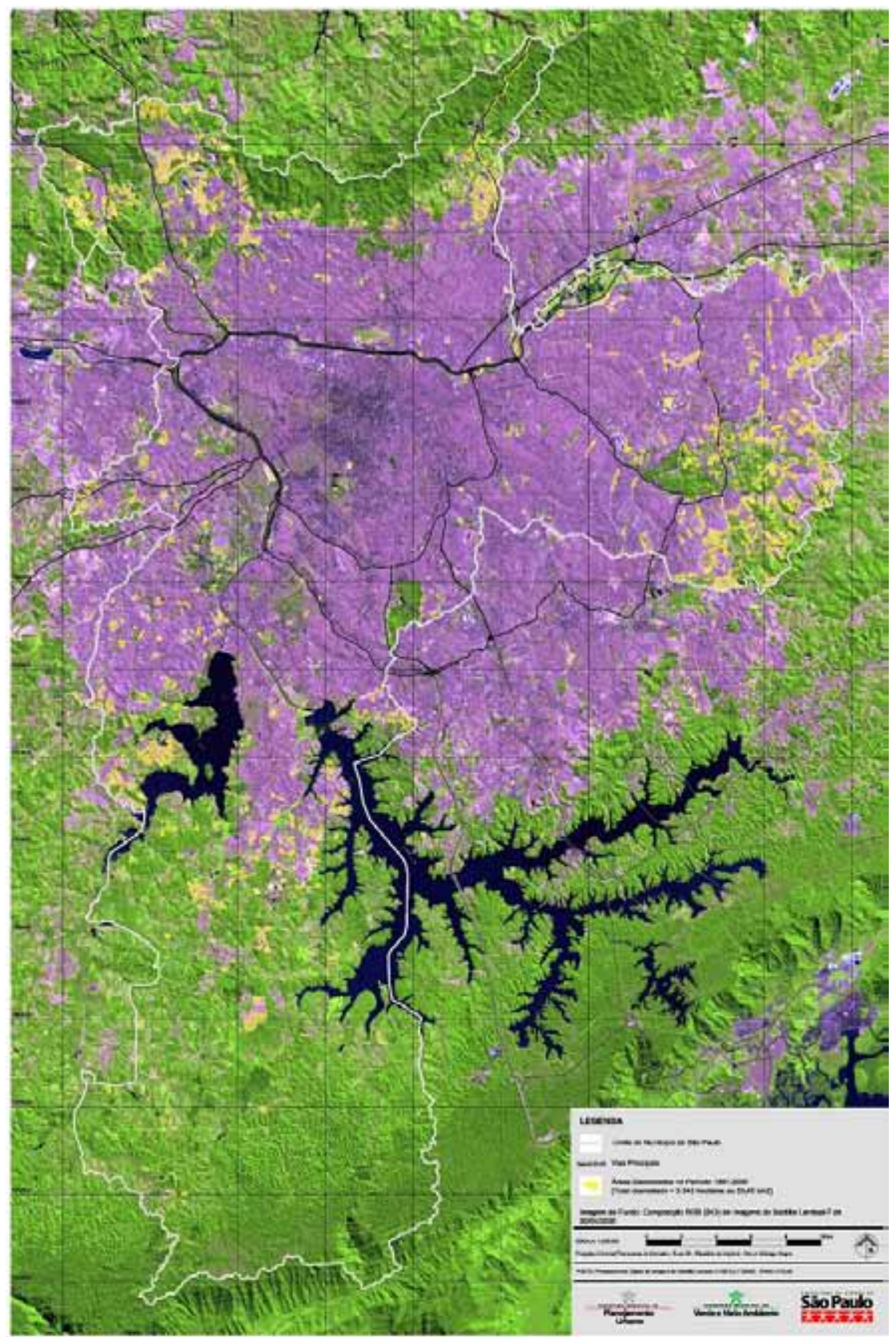


A Vegetação intercepta a radiação e produz sombra que também contribui para reduzir a liberação de calor urbano. A redução e fragmentação de grandes áreas de vegetação, não só reduz os benefícios para a qualidade de vida, mas também inibe o resfriamento atmosférico devido à circulação de ar gerado pela temperatura entre as áreas vegetadas e urbanizadas. Outros fatores, tais como a produção de calor a partir de ar condicionado, assim como, a partir de processos industriais e de tráfego de veículos motorizados e a obstrução do fluxo do ar por razão das superfícies edificadas, têm sido reconhecidos como causas adicionais do efeito de ilhas de calor (http://www. urbanheatislands.com/).

A promoção de estratégias para mitigar o efeito de ilha de calor é uma grande preocupação. Existem estratégias de redução de ilhas de calor: em primeiro lugar aumentar a refletividade de superfície, a fim de reduzir a absorção de radiação de superfícies urbanas e segundo, aumentar a cobertura de vegetação, a fim de maximizar os benefícios da vegetação em controlar o aumento da temperatura.

A criação de redes que conectam paisagens é de extrema importância, tornando a criação da Infraestrutura verde resposta ao novo paradigma de urbanização sustentável, cuja base é a permeabilidade dos serviços ecológicos e da paisagem natural em ambientes construídos, de modo que seja possível o desenvolvimento urbano e as intervenções de projetos em consonância com as questões ambientais e socioculturais.

\section{O PROJETO E A INTENÇÃO}

Nos dias de hoje, todo espaço vazio é alvo fácil para um frenesi de preencher, tapar. Mas, a meu ver, dois motivos concorrem para fazer dos espaços urbanos vazios, no mínimo, uma linha importante de combate, se não a única, para as pessoas que se preocupam com a cidade.

Rem KoOLhaAs, 1989

Hoje, para projetar é preciso descobrir elementos com os quais se possam criar novas formas para a condição urbana, preocupando-se com a análise da situação do local, para determinar a condição ambiental do território em receber uma intervenção. Controlar o sistema de espaços vazios, entendendo a paisagem surgirá uma nova 
concepção de cidade, definida por seus espaços vazios ou espaços verdes, trazendo ao projeto a essência do contexto ambiental.

"Se compreendermos que o projeto manifesta a intenção humana, e se o que fazemos com nossas mãos deve ser sagrado e honrar a terra que nos dá vida, então as coisas que fazemos não devem apenas erguer-se do chão, mas retornar a ele, o solo voltar ao solo, a água voltar à água, de modo que todas as coisas recebidas da terra possam ser livremente restituídas sem causar dano a qualquer sistema vivo. Isso é ecologia. Isso é um bom projeto"

William Mcdonough, 1993

Tadao Ando (1991) reconhece que a arquitetura cria uma nova paisagem e por isso tem a responsabilidade de ressaltar as características particulares de um determinado lugar e afirma que a finalidade da arquitetura é basicamente a construção do lugar. Essa leitura entre a paisagem e a construção leva a uma reflexão sobre a possibilidade de trabalhar diferentes escalas enquanto definição de projeto.

A criação arquitetônica supõe a contemplação das origens, compreende a importância vital de conceber uma arquitetura que não desfigure a grandeza da paisagem local e crie uma nova paisagem com o mínimo de dano. Ainda segundo Ando (1991) "O ponto de partida de um problema arquitetônico - seja o lugar, a natureza, o estilo de vida ou a história - se expressa na evolução para o abstrato".

Perceber a natureza em uma arquitetura construída com lógica deriva da reflexão dos elementos naturais - água, vento, luz sem se opor à sua geografia, buscando uma associação íntima entre a construção e a natureza num contexto de inter-relação do homem com a natureza. Não há uma demarcação clara entre interior e exterior, mas uma permeabilidade recíproca.

“(...) A arquitetura contemporânea tem um papel a cumprir no sentido de proporcionar às pessoas lugares arquitetônicos que as façam sentir a presença da natureza. Quando isso acontece, a arquitetura transforma a natureza por meio da abstração e modifica seu significado. Quando a água, o vento, a luz, a chuva e outros elementos naturais são abstraídos na arquitetura, esta se transforma em um lugar no qual as pessoas e a natureza se defrontam em permanente estado de tensão. Creio ser esse sentimento de tensão que poderá despertar as sensibilidades espirituais latentes no homem contemporâneo. (TADAO ANDO, 1991)." 

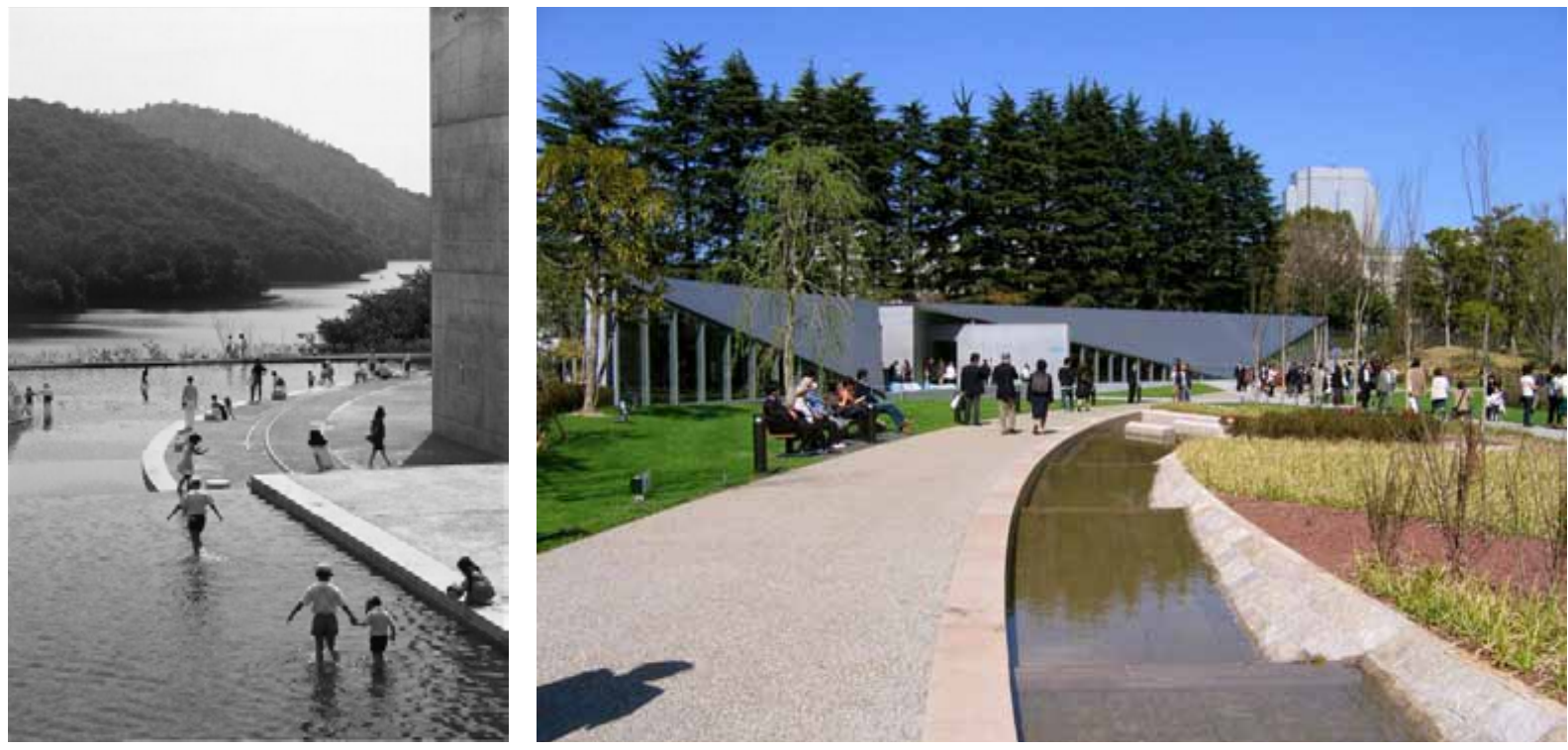

Museu da Criança, Himeji, 1987 - Tadao Ando.

A presença da arquitetura cria inevitavelmente uma nova paisagem, implicando a necessidade de descobrir a arquitetura que o próprio sítio está pedindo, num esforço para criar uma paisagem jogando com as características do lugar, procurando a lógica essencial este lugar, ao lado de suas tradições culturais, com a estrutura da cidade constituindo seu pano de fundo.

\section{CONSIDERAÇÕES FINAIS}

A arquitetura contemporânea tem um papel a cumprir. Norberg-Sculz (1976) diz que nosso mundo da vida cotidiana consiste em fenômenos concretos, mas também compreendem fenômenos menos tangíveis, como os sentimentos. Que as coisas concretas se inter-relacionam de modo complexo e talvez contraditório e que de maneira geral alguns fenômenos formam um ambiente para outros e juntas, essas coisas determinam uma "qualidade ambiental" que é a essência do lugar. "Portanto, um lugar é um fenômeno qualitativo "total", que não pode se reduzir a nenhuma de suas propriedades, como as relações espaciais, sem que se perca de vista sua natureza concreta".

"O propósito existencial do construir (arquitetura) é fazer um sítio tornar-se um lugar, isto é, revelar os significados presentes de modo latente no ambiente dado" (NORBERG-SCHULZ, 1976). 
Kongjian Yu (2006) argumenta que a era atual é marcada pela globalização e a propagação do materialismo e que isso traz grandes desafios e oportunidades para a arquitetura e faz uma série de questionamentos: Podemos sobreviver a rápida deterioração do ambiente e da ecologia? O que isso pode significar para a profissão de arquitetura, como posicionar-se para enfrentar estes desafios sem precedentes, como a arquitetura pode assumir o papel de proteger e reconstruir conexões espirituais através do projeto do nosso ambiente físico? Esta talvez seja a mais desafiadora de todas as perguntas.

A Arquitetura é possivelmente a mais legítima profissão entre aquelas que lidam com nosso ambiente físico, possibilitando recuperar a nossa identidade cultural e reconstruir a ligação espiritual entre pessoas e suas terras. A força da arquitetura reside na sua intrínseca associação com os sistemas naturais através da evolução.

Novas estratégias devem liderar o caminho do desenvolvimento urbano, identificando e planejando antes de executar. A infraestrutura da paisagem é fundamental na proteção dos processos ecológicos e nas heranças culturais que dão a nossa identidade cultural e alimentam nossas necessidades espirituais.

O crescimento urbano convencional é frequentemente visto como um processo horizontal, enquanto que a análise de aptidão ecológica é visto como um processo vertical. O desenvolvimento da ecologia que se concentra em padrões de paisagem, nos processos horizontais e na mudança no tempo, nos fornece fundamentos para o desenvolvimento da infraestrutura verde integrando os processos horizontais de desenvolvimento urbano com a proteção ecológica. Este é um novo modelo de planejamento ecológico em que na grande escala define o padrão de crescimento urbano e a forma da cidade; na escala intermediária define o sistema de espaço verde urbano que integra várias funções através dos espaços livres e dos meios de deslocamentos e na pequena escala define a estrutura para possibilitar o desenvolvimento da terra urbana orientando o desenho específico de cada local.

Esta infraestrutura verde torna-se um sistema integrado de vários processos, trazendo a natureza, o homem e o espírito juntos, com padrão de proteção eficiente para promover a integridade ecológica e ambiental, cultural e das pessoas. 


\section{BIBLIOGRAFIA}

ANDO, Tadao. Por novos horizontes na arquitetura (1991), in NESBIT, Kate (Org.). Uma nova agenda para a arquitetura: uma antologia teórica 1965-1995. São Paulo: CosacNaify, 2006, pp493-497.

BENEDICT, Mark A., MCMAHON, Edward T. Green infrastrustructure: linking landscapes and communits. Washington, DC: ISLAND PRESS, 2006.

FORMAN, Richard T.T. and GODRON, Michel. Landscape ecology. NY, John Wiley and Sons, 1986.

FORMAN, Richard T.T. Land Mosaics. The ecology of landscapes and regions. Cambridge: Cambridge University Press, 1995.

Kongjian Yu. The Art of Survival. American Society of Landscape Architects ASLA, 2006. Disponível em <http://www.urbanheatislands.com/>. Acesso em 04/05/2013.

KOOLHAAS, Rem. Para além do delírio (1993), in NESBIT, Kate (Org.). Uma nova agenda para a arquitetura: uma antologia teórica 1965-1995. São Paulo: CosacNaify, 2006, pp361-368

KOOLHAAS, Rem. Por uma cidade contemporânea (1989) in NESBIT, Kate (Org.). Uma nova agenda para a arquitetura: uma antologia teórica 1965-1995. São Paulo: CosacNaify, 2006, pp357-361

McDonough, William. Projeto, ecologia, ética e a produção das coisas (1993), in NESBIT, Kate (Org.). Uma nova agenda para a arquitetura: uma antologia teórica 19651995. São Paulo: CosacNaify, 2006, pp427-438.

NORBERG-SCHULZ, Christian. O fenômeno do lugar (1976) in NESBIT, Kate (Org.). Uma nova agenda para a arquitetura: uma antologia teórica 1965-1995. São Paulo: CosacNaify, 2006, pp443-461.

SANTOS, Rozely Ferreira dos. Planejamento Ambiental: teoria e prática. São Paulo: Oficina de Textos, 2004. 
TRES, Deisy Regina. Abordagem Sistêmica para restauração da paisagem. Tese apresentada ao Programa de Pós-Graduação em Recursos Genéticos Vegetais, Departamento de Fitotecnia, do Centro de Ciências Agrárias da Universidade Federal de Santa Catarina como requisito para a obtenção do título de Doutor em Ciências. Florianópolis, SC, 2010.

WHATELY, Marússia (Org.). Seminário Billings 2002. Avaliação e identificação de áreas prioritárias para a conservação, recuperação e uso sustentável da Bacia Hidrográfica da Billings. São Paulo: Instituto Socioambiental, 2003. 